\title{
Cervical insemination versus intra-uterine insemination of donor sperm for subfertility (Review)
}

\author{
Besselink DE, Farquhar C, Kremer JAM, Marjoribanks J, O’Brien PA
}

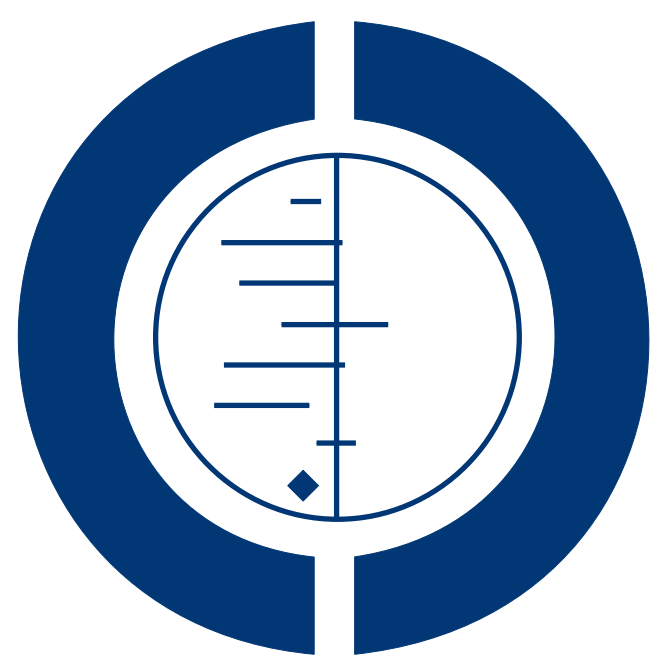

\section{THE COCHRANE COLLABORATION $^{\circledR}$}

This is a reprint of a Cochrane review, prepared and maintained by The Cochrane Collaboration and published in The Cochrane Library 2008, Issue 2

http://www.thecochranelibrary.com

\section{WILEY}


TABLE OF CONTENTS

HEADER

ABSTRACT

PLAIN LANGUAGE SUMMARY

BACKGROUND

OBJECTIVES

METHODS

RESULTS

DISCUSSION

Figure 1.

Figure 2.

AUTHORS' CONCLUSIONS

ACKNOWLEDGEMENTS

REFERENCES

CHARACTERISTICS OF STUDIES

DATA AND ANALYSES

Analysis 1.1. Comparison 1 IUI versus CI in stimulated cycles with cryopreserved sperm, Outcome 1 Live birth rate per woman after all treatment cycles.

Analysis 1.2. Comparison 1 IUI versus CI in stimulated cycles with cryopreserved sperm, Outcome 2 Live birth rate per woman after one treatment cycle.

Analysis 1.3. Comparison 1 IUI versus CI in stimulated cycles with cryopreserved sperm, Outcome 3 Pregnancy rate per woman after one treatment cycle.

Analysis 1.4. Comparison 1 IUI versus CI in stimulated cycles with cryopreserved sperm, Outcome 4 Pregnancy rate per woman after all treatment cycles.

Analysis 1.5. Comparison 1 IUI versus CI in stimulated cycles with cryopreserved sperm, Outcome 5 Miscarriage rate per woman.

Analysis 1.6. Comparison 1 IUI versus CI in stimulated cycles with cryopreserved sperm, Outcome 6 Multiple pregnancy rate per woman. . . . . . . . . . . . . . . . . . . . . . . . . . . . . . . . . . 25

ADDITIONAL TABLES . . . . . . . . . . . . . . . . . . . . . . . . . . . . . . . . . . . 25

WHAT'S NEW . . . . . . . . . . . . . . . . . . . . . . . . . . . . . . . . . . . . . . 26

HISTORY . . . . . . . . . . . . . . . . . . . . . . . . . . . . . . . . . . . . . . 26

CONTRIBUTIONS OF AUTHORS . . . . . . . . . . . . . . . . . . . . . . . . . . . . . . . . . .

DECLARATIONS OF INTEREST . . . . . . . . . . . . . . . . . . . . . . . . . . . . . . . . . . . .

SOURCES OF SUPPORT . . . . . . . . . . . . . . . . . . . . . . . . . . . . . . . . . . . . . . . . . . . . . .

NOTES . . . . . . . . . . . . . . . . . . . . . . . . . . . . . . . . . . 27

INDEX TERMS . . . . . . . . . . . . . . . . . . . . . . . . . . . . . . . . . . . .

Cervical insemination versus intra-uterine insemination of donor sperm for subfertility (Review)

Copyright $\odot 2010$ The Cochrane Collaboration. Published by John Wiley \& Sons, Ltd. 


\title{
nancint \\ Cervical insemination versus intra-uterine insemination of donor sperm for subfertility
}

\author{
Dagmar E. Besselink ${ }^{1}$, Cindy Farquhar ${ }^{2}$, Jan AM Kremer ${ }^{3}$, Jane Marjoribanks ${ }^{4}$, Paul A O’Brien ${ }^{5}$ \\ ${ }^{1}$ Medicine, Radboud University, Nijmegen, Netherlands. ${ }^{2}$ Obstetrics and Gynaecology, University of Auckland, Auckland, New \\ Zealand. ${ }^{3}$ Obstetrics \& Gynaecology, Radboud University Nijmegen Medical Centre, Nijmegen, Netherlands. ${ }^{4}$ Obstetrics and Gynae- \\ cology, Cochrane Menstrual Disorders and Subfertility Group, Auckland, New Zealand. ${ }^{5}$ Westside Contraceptive Services, London \\ Community Healthcare, London, UK
}

Contact address: Dagmar E. Besselink, Medicine, Radboud University, Joh. Vijghstraat 3, 6524 BN, Nijmegen, Netherlands. d.e.Besselink@student.ru.nl.

Editorial group: Cochrane Menstrual Disorders and Subfertility Group.

Publication status and date: Edited (no change to conclusions), published in Issue 11, 2010.

Review content assessed as up-to-date: 16 February 2008.

Citation: Besselink DE, Farquhar C, Kremer JAM, Marjoribanks J, O’Brien PA. Cervical insemination versus intra-uterine insemination of donor sperm for subfertility. Cochrane Database of Systematic Reviews 2008, Issue 2. Art. No.: CD000317. DOI: 10.1002/14651858.CD000317.pub3.

Copyright (C) 2010 The Cochrane Collaboration. Published by John Wiley \& Sons, Ltd.

\begin{abstract}
A B S T R A C T
Background

Insemination with donor sperm is an option for couples for whom in vitro fertilisation (IVF) or intra-cytoplasmic sperm injection (ICSI) has been unsuccessful, couples with azoospermia and for single women or same sex couples.

Insemination of sperm can be done via cervical (CI) or intra-uterine (IUI) routes. IUI has been considered potentially more effective than $\mathrm{CI}$ as the sperm bypasses the cervical mucus and is deposited closer to the fallopian tubes. The cost and risks of IUI may be higher because of the need for sperm preparation and the introduction of foreign material into the uterus.

Donor sperm used for artificial insemination is mainly cryopreserved, due to concerns about HIV transmission. However, cycle fecundity is higher for fresh sperm. Insemination is often combined with ovulatory stimulation, with either clomiphene or gonadotrophin. There may be risks associated with these therapies, such as higher multiple pregnancy rates.
\end{abstract}

\section{Objectives}

To determine whether pregnancy outcomes are improved using intra-uterine insemination in comparison to cervical insemination in women undergoing artificial insemination with donor sperm.

\section{Search methods}

The following databases were searched: the Cochrane Menstrual Disorders and Subfertility Group Specialised Register, CENTRAL (The Cochrane Library), MEDLINE, EMBASE, CINAHL and the reference lists of articles retrieved.

\section{Selection criteria}

Randomised controlled trials comparing IUI with CI were included. Crossover studies were included if pre-crossover data was available.

Data collection and analysis

Study quality assessment and data extraction were carried out independently by two review authors (DB, JM). Authors of studies that potentially met the inclusion criteria were contacted, where possible if additional information was needed.

Cervical insemination versus intra-uterine insemination of donor sperm for subfertility (Review)

Copyright @ 2010 The Cochrane Collaboration. Published by John Wiley \& Sons, Ltd. 


\section{Main results}

The search strategy found 232 articles. Fifteen studies potentially met the inclusion criteria. Four studies were included in this review. All the included studies used cryopreserved sperm in stimulated cycles. In two studies 134 women had gonadotrophin-stimulated cycles and in two studies 74 women had clomiphene-stimulated cycles. The evidence showed that IUI after 6 cycles significantly improved live birth rates (odds ratio (OR) 1.98, 95\% confidence interval (CI) 1.02 to 3.86) and pregnancy rates (OR 3.37, 95\% CI 1.90 to 5.96) in comparison to cervical insemination. There was no statistically significant evidence of an effect on multiple pregnancies (OR 2.19, $95 \%$ CI 0.79 to 6.07 ) or miscarriages (relative risk (RR) $3.92,95 \%$ CI 0.85 to 17.96 ).

\section{Authors' conclusions}

The findings of this review support use of IUI rather than CI in stimulated cycles using cryopreserved sperm for donor insemination.

\section{PLAIN LANGUAGE SUMMARY}

\section{Cervical insemination versus intra-uterine insemination of donor sperm for subfertility}

Insemination of donor sperm is a fertility treatment for women who are unable to conceive with their partner or are single. There are two techniques of insemination; the sperm can be deposited either in the cervix or in the uterus. The purpose of this review is to determine whether pregnancy outcomes are improved using intra-uterine insemination (IUI) in comparison to cervical insemination (CI) in women undergoing insemination with donor sperm. Of the 232 studies found, four studies were included in this review. All of the included studies used cryopreserved sperm. In two studies women had gonadotrophin-stimulated cycles and in two studies women had clomiphene-stimulated cycles. The rates of live birth and pregnancy improved with IUI. Therefore, this review supports the use of IUI instead of CI for donor insemination.

\section{B A C K G ROU N D}

Artificial insemination with donor sperm is used for various causes of subfertility. Ten per cent of the couples who try to conceive a child will not have a spontaneous conception within a year ( Taylor 2003) and can thus be considered subfertile. A part of this subfertility is due to severe male factor infertility. Insemination with donor sperm is a method for these couples to overcome the male factor. Insemination with donor sperm is also an option for couples for whom in vitro fertilisation (IVF) or intracytoplasmic sperm injection (ICSI) has been unsuccessful (Gorrill 2003) and for single women or same sex couples who want to have a child.

There are two techniques of insemination. With cervical insemination (CI) sperm is deposited at the external cervical os, while with intra-uterine insemination (IUI) the sperm is deposited in the uterine cavity. IUI may be more effective than CI as the sperm bypasses the cervical mucus and is deposited closer to the fallopian tubes, which may increase the number of sperm reaching the site of fertilisation (Ripps 1994). However, IUI may have some disadvantages. In contrast to CI, the sperm used for IUI need to be prepared in the laboratory, which leads to a loss of sperm during the process. There are several preparation techniques, with no clear evidence that one specific technique is superior to any other (Boomsma 2004). IUI also requires manipulation with an intra-uterine catheter, involving the possible introduction of foreign material to the uterus. The cost and the risks (infection and anaphylaxis) of IUI may, therefore, be higher.

The donor sperm used for artificial insemination is mainly cryopreserved, due to concern about human immunodeficiency virus (HIV) transmission: fresh sperm may still be used outside of the fertility clinic by single women or same sex couples who obtain donor sperm from an acquaintance. The use of cryopreserved sperm, quarantined for six months, is the standard technique (British 1999). However, cycle fecundity is lower for cryopreserved sperm than for fresh sperm (Subak 1992). This is due to detrimental effects of the freeze-thaw procedure as structural and functional changes result in a decrease in sperm motility, velocity and viability (Sharma 1997).

Artificial insemination is often combined with ovulation stimulation therapy. This can be achieved with clomiphene, an antiestrogen, or with gonadotrophin. Through the use of these drugs the follicular growth is stimulated. There are risks associated with these therapies, such as multiple pregnancy rates that range be- 
tween 10\% and 40\% (Fauser 2005) and ovarian hyperstimulation syndrome (Delvigne 2002).

The purpose of this review was to collect evidence on the comparison of CI and IUI. This review is an update of a previous review (O’Brien 1998), according to contemporary Cochrane guidelines (Higgins 2006).

\section{O B JEC T IVES}

To determine whether pregnancy outcomes are improved using intra-uterine insemination in comparison to cervical insemination in women undergoing artificial insemination with donor sperm.

\section{METHODS}

\section{Criteria for considering studies for this review}

\section{Types of studies}

- Only truly randomised trials were included. Trials with quasi-randomisation were excluded.

- Crossover trials were included only if pre-crossover data was obtained.

\section{Types of participants}

- Women undergoing donor insemination for any reason, including couples with male factor infertility, couples with a history of failed IVF or ICSI, single women, same sex couples.

\section{Types of interventions}

- IUI versus $\mathrm{CI}$ in natural cycles with cryopreserved sperm

- IUI versus CI in clomiphene-stimulated cycles with cryopreserved sperm

- IUI versus CI in gonadotrophin-stimulated cycles with cryopreserved sperm

- IUI versus $\mathrm{CI}$ in natural cycles with fresh sperm

- IUI versus CI in clomiphene-stimulated cycles with fresh sperm

- IUI versus CI in gonadotrophin-stimulated cycles with fresh sperm

\section{Types of outcome measures}

Main outcome

- Live birth rate per woman after all cycles
- Live birth rate per woman after one treatment cycle

- Ongoing pregnancy rate per woman after one treatment cycle

- Pregnancy rate per woman after one treatment cycle

- Ongoing pregnancy rate per woman after all cycles

- Pregnancy rate per woman after all cycles

Adverse outcomes

- Miscarriage rate per woman

- Ectopic pregnancy rate per woman

- Multiple pregnancy per woman

- Infection rate per woman

- Adverse effects rate per woman

Outcomes as stated by a study were also assessed.

\section{Search methods for identification of studies}

We searched the following sources for all reports that described (or might have described) randomised controlled trials of IUI in comparison with CI: Cochrane Menstrual Disorders and Subfertility Group Specialised Register, Cochrane Central Register of Controlled Trials (CENTRAL) (The Cochrane Library 2006, Issue 4), MEDLINE (1966 to week 3, 2007), EMBASE (1980 to week 3, 2007), CINAHL (1982 to week 50, 2006) and the reference lists of articles retrieved.

We used the search strategy developed by the Menstrual Disorders and Subfertility Group (see Review Group details in The Cochrane Library for more information). The specific search strings used are listed below.

MEDLINE

1 randomized controlled trial.pt.

2 controlled clinical trial.pt.

3 Randomized controlled trials/

4 random allocation/

5 double-blind method/

6 single-blind method/

7 or/ $1-6$

8 clinical trial.pt.

9 exp clinical trials/ )

10 (clin\$ adj25 trial\$).ti,ab,sh.

11 ((singl\$ or doubl\$ or tripl\$ or trebl\$) adj25 (blind $\$$ or mask\$)).ti,ab,sh.

12 placebos/

13 placebo\$.ti,ab,sh.

14 random $\$ . t i, a b, s h$

15 Research design/

16 or/8-15

$17 \mathrm{animal} /$ not (human/ and animal/)

187 or 16

1918 not 17

20 exp Insemination, Artificial/

21 inseminat\$.ti,ab,sh.

Cervical insemination versus intra-uterine insemination of donor sperm for subfertility (Review) 
22 eutelegenesis.ti,ab,sh.

23 or/ $20-22$

24 IUI.ti,ab,sh.

25 intrauterine.ti,ab,sh.

26 intra-uterine.ti,ab,sh.

27 or/24-26

28 cervical.ti,ab,sh.

29 intracervical.ti,ab,sh.

30 intra-cervical.ti,ab,sh.

31 pericervical.ti,ab,sh.

32 peri-cervical.ti,ab,sh.

33 cap.ti,ab,sh.

34 or/28-33

3523 and 27 and 34

3619 and 35

37 from 36 keep 1-58

EBM Reviews - Cochrane Central Register of Controlled Trials (CENTRAL)

1 artificial insemination/ or intrauterine insemination/

2 inseminat $\$ . m p$.

3 or/ $1-2$

4 intrauterine insemination/

5 IUI.mp.

6 intrauterine.mp.

7 intra-uterine.mp.

8 or/4-7

9 cervical.mp.

10 intracervical.mp.

11 intra-cervical.mp.

12 pericervical.mp.

13 peri-cervical.mp.

14 cap.mp.

15 or/9-14

163 and 8 and 15

17 from 16 keep 1-51

CINAHL - Cumulative Index to Nursing \& Allied Health Liter-

ature

1 artificial insemination/ or intrauterine insemination/

2 inseminat\$.mp.

3 or $/ 1-2$

4 intrauterine insemination/

5 IUI.mp.

6 intrauterine.mp.

7 intra-uterine.mp.

8 or/4-7

9 cervical.mp.

10 intracervical.mp.

11 intra-cervical.mp.

12 pericervical.mp.

13 peri-cervical.mp.

14 cap.mp.

15 or/9-14
163 and 8 and 15

17 Controlled study/ or randomized controlled trial/

18 double blind procedure/

19 single blind procedure/

20 crossover procedure/

21 drug comparison/

22 placebo/

23 random\$.ti,ab,hw,tn,mf.

24 latin square.ti,ab,hw,tn, mf.

25 crossover.ti,ab,hw,tn, mf.

26 cross-over.ti,ab,hw,tn,mf.

27 placebo\$.ti,ab,hw,tn, $\mathrm{mf}$.

28 ( (doubl\$ or singl\$ or tripl\$ or trebl\$) adj5 (blind\$ or mask\$)).ti,ab,hw,tn, mf.

29 (comparative adj5 trial\$).ti,ab,hw,tn, mf.

30 (clinical adj5 trial\$).ti,ab,hw,tn, mf.

31 or/17-30

32 nonhuman/

33 animal/ not (human/ and animal/)

$34 \mathrm{or} / 32-33$

3531 not 34

3616 and 35

37 from 36 keep 1

EMBASE

1 artificial insemination/ or intrauterine insemination/

2 inseminat\$.mp. 3 or/1-2

4 intrauterine insemination/

5 IUI.mp.

6 intrauterine.mp.

7 intra-uterine.mp.

8 or/4-7

9 cervical.mp.

10 intracervical.mp.

11 intra-cervical.mp.

12 pericervical.mp.

13 peri-cervical.mp.

14 cap.mp.

15 or $/ 9-14$

163 and 8 and 15

17 Controlled study/ or randomized controlled trial/

18 double blind procedure/

19 single blind procedure/

20 crossover procedure/

21 drug comparison/

22 placebo/

23 random\$.ti,ab,hw,tn, mf.

24 latin square.ti,ab,hw,tn, mf.

25 crossover.ti,ab,hw,tn, mf.

26 cross-over.ti,ab,hw,tn, mf.

27 placebo\$.ti,ab,hw,tn, mf.

28 ( (doubl\$ or singl\$ or tripl\$ or trebl\$) adj5 (blind\$ or mask\$)).ti,ab,hw,tn,mf.

Cervical insemination versus intra-uterine insemination of donor sperm for subfertility (Review)

Copyright $\odot 2010$ The Cochrane Collaboration. Published by John Wiley \& Sons, Ltd. 
29 (comparative adj5 trial\$).ti,ab,hw,tn, mf.

30 (clinical adj5 trial\$).ti,ab,hw,tn, mf.

31 or/ $17-30$

32 nonhuman/

33 animal/ not (human/ and animal/)

34 or $/ 32-33$

3531 not 34

3616 and 35

37 from 36 keep 1-85

\section{Data collection and analysis}

DE Besselink and J Marjoribanks independently selected the trials to be included according to the above-mentioned criteria. They also independently extracted all data. Disagreements were resolved by discussion with Professor Farquhar as referee. Professor Dr JAM Kremer acted as a clinical expert.

Included trials were analysed for the following quality criteria and methodological details. A quality table was made to assess the methodology. If additional information was needed, the authors of the articles were contacted.

\section{Trial characteristics}

- Quality of allocation concealment (score according to Cochrane standards)

- Method of randomisation

- Crossover or parallel design

- Number of women eligible, randomised, excluded or lost to follow up

- Details on dropouts

- Presence of a power calculation

- Number and percentage of cancelled cycles

- Duration, timing and location (single or multicentre) of the study

- Whether an intention-to-treat analysis was done or could be extracted

- Funding

\section{Types of participants}

- Indication for insemination

- Women's age

- Duration of subfertility

\section{Types of ovulation cycles \\ - Natural cycles \\ - Clomiphene-stimulated cycles \\ - Gonadotrophin-stimulated cycles}

\section{SAME AS ABOVE (CHARACTERISTICS OF INCLUDED STUDIES)}

\section{Statistical analysis}

Binary data for each comparison and each study are summarised in two-by-two tables and expressed as odds ratios (OR) with 95\% confidence intervals (CI). Data was pooled and a meta-analysis performed with RevMan software using the Peto-modified Mantel-Haenszel method and a fixed-effect model.

Statistical heterogeneity between the results of different studies was examined by inspecting the scatter in the data points on the graphs and the overlap in their confidence intervals, and by checking the Chi-squared tests and $\mathrm{I}^{2}$ statistic. When statistically significant heterogeneity was found (Chi-squared test $\mathrm{P}<0.05)$ a randomeffects model would have been used as well as the fixed-effect model.

When substantial heterogeneity was detected (I2 greater than $75 \%$ ) or if trials differ markedly with respect to clinical or design characteristics, then sensitivity analyses would have been undertaken. To detect publication bias a funnel graph, plotting effect size versus sample size, would have been performed if sufficient studies were available.

Sensitivity analyses

Specific differences that we planned to explore were trials with adequate methodology versus those of poor methodology; where adequate methodology was defined for this purpose as secure randomisation, adequate allocation concealment, analysis by intention to treat, and losses to follow up of less than $10 \%$. Further sensitivity analyses would have been performed on trials that might differ from others with respect to prognostic factors at baseline. Sensitivity analyses would also have compared couples with or without a history of infertility.

Subgroup analyses

No subgroup analyses were done.

Changes to original review

There are two major changes to the original review. First, studies with a crossover design were only included if they could provide pre-crossover data. Authors were contacted to obtain the precrossover data, if necessary. The reason for the change is that studies with a crossover design are not appropriate when the outcome is irreversible (Higgins 2006), as it is with pregnancy. The outcome will prevent the woman from crossing over and an intraparticipant comparison will be impossible. Furthermore, women who remain under treatment after the first cycle have, on average, lower fecundity that those who conceived during the first cycle; because those of highest fecundity are no longer 'at risk' of pregnancy. All these factors can lead to an exaggeration of the more successful treatment effect (Lechmacher 1991).

The other major change in the present review is that the outcomes were stated per woman instead of per cycle. This way the compared groups are statistically independent. 


\section{Description of studies}

See: Characteristics of included studies; Characteristics of excluded studies.

The search strategy described above found 85 articles with EMBASE, 58 articles with MEDLINE, 51 articles with CENTRAL, 37 articles in the Cochrane Menstrual Disorders and Subfertility Group Specialised Register and one article with CINAHL. DB screened the findings and retrieved 15 studies that potentially met the inclusion criteria. DB and JM checked these in full text for eligibility and found four to be eligible.

Included studies

Four studies were included in this review. All of the included studies used cryopreserved sperm. In two studies women had gonadotrophin-stimulated cycles (Wainer 1995; Matorras 1996). In the other two studies women had clomiphene-stimulated cycles (Patton 1992; Hurd 1993)

\section{Characteristics of participants \\ - Participants}

In the two studies where gonadotrophin stimulation was used there were a total of 134 women. Both studies inseminated a maximum of six times (Wainer 1995; Matorras 1996). Of the studies with clomiphene stimulated cycles, one had 48 women in the studies and inseminated also a maximum of six cycles (Patton 1992). The other study using clomiphene-stimulated cycles was a crossover study (Hurd 1993) with 26 women receiving CI or IUI only once before crossing over.

\section{- Indication}

All studies included couples with male factor infertility namely azoospermia and oligospermia. Wainer 1995 also included one couple with a genetic indication and two studies also included single women (Patton 1992; Hurd 1993). Only Matorras 1996 reported criteria for a maximum sperm count.

\section{- Inclusion criteria}

All the studies performed hysterosalpingography on the women (Patton 1992; Hurd 1993; Wainer 1995; Matorras 1996) but Patton 1992 performed them only on women with a historical risk and excluded the women with an abnormal hysterosalpingography. Three studies evaluated women with basal body temperature charts (Patton 1992; Hurd 1993; Wainer 1995). Hurd 1993 also evaluated 15 patients by laparoscopy of whom seven were treated before the start of the study with laser laparoscopy for tubal adhesions (two women) or endometriosis grade I (two women) or grade II (three women). Women were excluded who had ovulatory dysfunction not corrected by clomiphene. Patton 1992 performed an additional urinary luteinising hormone (LH) assay on the women.

Matorras 1996 performed an endometrial biopsy, determination of $\mathrm{P}$ and PRL and sperm analysis. Couples were included if they had an infertility history of $>2$ years, at least one patent tube, woman's age $<40$ years and an abnormal sperm analysis of $<1.5$ X 106 motile sperm after Percoll preparation. Wainer 1995 performed an additional analysis of the cervical mucus and hormonal screening. Women were included in the study if they had no other fertility problem except slight ovulation dysfunction.

\section{- Age}

One study could not provide us with the ages of the separate intervention groups before crossover, but the overall mean (SD) age was 32 (4) years (Hurd 1993). In the other three studies the ages of the women were similar with means between 30 and 32 years.

\section{- Duration of infertility}

Only one study stated the average duration of infertility (Matorras 1996). The couples in the CI group had an infertility history (SD) of 5.97 (3.13) years and the couples in the IUI group had an infertility history (SD) of 7.81 (3.75) years.

\section{- Previous treatment}

Wainer 1995 was the only study that stated women's previous treatments. There was one woman in the CI group who had a live birth after CI and two women in the IUI group who had previously received CI, of whom one woman had a live birth and one woman had a miscarriage.

\section{- Characteristics of intervention}

None of the included studies used fresh sperm for the insemination. All of the studies stimulated cycles with either clomiphene or gonadotrophin. Only one study stated the number of women receiving cycle induction per intervention group, in which 13 of 22 women in the CI group and 6 of 28 women in the IUI group received clomiphene (Patton 1992). In the other study where clomiphene was used, 23 of 41 women received treatment (Hurd 1993) but it was not stated per intervention group. The study also compared IUI and CI with a third treatment namely intratubal insemination combined with IUI.

The two studies that compared IUI versus CI in gonadotrophinstimulated cycles did not state how many women, in total or in each group, received gonadotrophin (Wainer 1995; Matorras 1996).

The studies that used clomiphene for cycle induction inseminated both intervention groups at LH + 1 day (Patton 1992; Hurd 1993). The studies that used gonadotrophin inseminated the CI group twice at LH +12 hours and 36 (Matorras 1996) or 38 hours (Wainer 1995) and the IUI group once at 36 hours (Matorras 1996) or 38 hours (Wainer 1995).

\section{- Characteristics of outcome measures}

All of the studies defined pregnancy by the visualisation of a gestational sac. Two studies also measured serum human chorionic gonadotrophin (hCG) to confirm pregnancy (Patton 1992; Hurd 1993).

The primary outcome of live birth rates was presented by all but one study (Hurd 1993; Wainer 1995; Matorras 1996). All studies 
reported pregnancy rates per woman after all insemination cycles. Two studies also provided pregnancy rates per woman after one treatment cycle (Patton 1992; Wainer 1995) as well as the crossover study as it provided data of only one cycle (Hurd 1993).

Only one study failed to report any adverse outcomes (Patton 1992). The other three studies provided data on miscarriage and multiple pregnancy rates (Hurd 1993; Wainer 1995; Matorras 1996). One study also reported ectopic rates (Hurd 1993). None of the studies reported on infections or other adverse effects of the inseminations.

\section{Risk of bias in included studies}

\section{Excluded studies}

Eleven studies were excluded. Studies that were unable to provide pre-crossover data were excluded from this update (Urry 1988; Byrd 1990; Patton 1990; Ract 1992; Peters 1993; Alexander 1994; Williams 1995; Pistorius 1996; Carroll 2001). This included studies that were in the original Cochrane review. The reasons for excluding these crossover studies are outlined in the 'Methods of the review' section. Carroll 2001 and Peters 1993 were excluded because they used quasi-randomisation methods; both studies allocated by alternation. Le Lannou 1989 and Walker 1993 were excluded because of their method of comparison; they compared IUI using gonadotrophin-stimulated cycles with CI using un stimulated cycles (Walker 1993) or with a proportion (Le Lannou 1989) of un stimulated cycles. This made it impossible to judge the specific effects of IUI versus CI per se.

\section{- Allocation concealment}

Hurd 1993 and Matorras 1996 used opaque, consecutively numbered lists to conceal allocation and provided no further information. The other studies did not state if or how allocation was concealed (Patton 1992; Wainer 1995).

\section{- Randomisation method}

Three studies used random number lists to randomise the women (Hurd 1993; Wainer 1995; Matorras 1996). It was not clear how the randomisation procedure in Patton 1992 was performed.

\section{- Study design}

Three studies used a parallel design (Patton 1992; Wainer 1995; Matorras 1996). Attempts were made to contact authors of studies with a crossover design to obtain pre-crossover data. Only one study provided pre-crossover data and could therefore be included in the review (Hurd 1993).

\section{- Blinding of treatment}

The procedure of blinding was not mentioned in any of the studies.

Blinding of donor selection was stated in only one study (Wainer 1995), where centres supplying the semen were blind to the method of insemination.

- Dropouts and intention-to-treat analysis
Two studies reported no dropouts (Hurd 1993; Matorras 1996). One study did not report dropout rates (Wainer 1995). In Patton 1992 seven women dropped out before the first insemination and 12 women were eliminated from analyses; four were excluded because of more than a single route of insemination, two women because they received more than one insemination per cycle, four women because of uterine structural anomalies and two women were excluded because they used gonadotrophin. Hurd 1993 stated in the correspondence that analysis was done by intention to treat.

\section{- Power calculation}

Only Matorras 1996 reported a power calculation but provided no further details. Hurd 1993 did not perform a power calculation. Wainer 1995 and Patton 1992 did not mention a power calculation.

\section{- Cancelled cycles}

None of the studies reported information on cancelled cycles.

- Duration, timing and location (single or multicentre) of the study

The included studies were all single-centre studies.

\section{Effects of interventions}

None of the included studies used fresh sperm. Therefore there are no results for the interventions comparing IUI and CI with fresh sperm. None of the included studies conducted inseminations in natural cycles.

IUI versus CI in stimulated cycles with cryopreserved sperm All the included studies used either clomiphene or gonadotrophinstimulated cycles with cryopreserved sperm. In total they compared 207 women, of whom 26 had only one insemination because of the crossover design of the trial. The other 181 women received up to six inseminations. The outcomes discussed in this section were only those where clomiphene as well as gonadotrophin-stimulated cycles were pooled. Pooled data for the separate stimulation regimes are discussed later in the review.

- Live birth rate per woman after all treatment cycles

Three studies with a total of 157 women reported live birth as an outcome. IUI gives a statistically significant higher live birth rate (OR $1.98,95 \%$ CI 1.02 to 3.86) statistical heterogeneity (P $\left.=0.84, \mathrm{I}^{2}=0 \%\right)$.

- Pregnancy rate per woman after one treatment cycle

Three studies with a total of 119 women reported pregnancy rate per woman after one treatment cycle. The difference was not statistically significant, there were five pregnancies in the CI group $(\mathrm{n}=55)$ and 12 pregnancies in the IUI group $(\mathrm{n}=64)(\mathrm{OR} 2.12$, $95 \%$ CI 0.76 to 5.95$)$ statistical heterogeneity $\left(\mathrm{P}=0.64, \mathrm{I}^{2}=0 \%\right)$.

- Pregnancy rate per woman after all treatment cycles

All the included studies reported pregnancy rate as an outcome. IUI gives a statistically significant higher pregnancy rate (OR 3.37, 
95\% CI 1.90 to 5.96$)$ statistical heterogeneity $\left(\mathrm{P}=0.42, \mathrm{I}^{2}=\right.$ $0.0 \%)$.

- Adverse outcomes

Three trials reported miscarriage and multiple pregnancy rates per woman but the differences found were not significant. None of the studies reported ectopic pregnancies rate, infection rate or adverse effects rate per woman.

- Miscarriage rate per woman

Three included studies reported miscarriage rate as an outcome. In total there were seven miscarriages. The difference was not statistically significant (OR 3.92, 95\% CI 0.85 to 17.96) statistical heterogeneity ( $\left.\mathrm{P}=0.78, \mathrm{I}^{2}=0 \%\right)$.

- Multiple pregnancy rate per woman

Three included studies reported multiple pregnancy as an outcome. There were 12 multiple pregnancies in the IUI group and five multiple pregnancies in the CI group. The difference in multiple pregnancy rate was not statistically significant (OR 2.19, 95\% CI 0.79 to 6.07$)$ statistical was heterogeneity $\left(\mathrm{P}=0.87, \mathrm{I}^{2}=0 \%\right)$ IUI versus $\mathrm{CI}$ in clomiphene-stimulated cycles with cryopreserved sperm

There were two included studies that compared IUI and CI in clomiphene-stimulated cycles with cryopreserved sperm (Patton 1992; Hurd 1993). In total they compared 76 women of whom 26 had only one insemination, because of the crossover design of the trial. The other 50 women could receive up to six inseminations.

- Live birth rate per woman after all treatment cycles

One study reported pregnancy rate after all treatment cycles, but only one cycle was performed. The study reported one pregnancy in the IUI group $(\mathrm{n}=13)$ as well as in the CI $(\mathrm{n}=13)$ group (OR $1.00,95 \% 0.06$ to 16.93$)$.

- Live birth rate per woman after one treatment cycle

One study reported pregnancy rate after one treatment cycle and reported one pregnancy in the IUI group $(n=13)$ as well as in the CI ( $\mathrm{n}=13)$ group (OR 1, 95\% 0.06 to 16.93$)$.

- Ongoing pregnancy rate per woman after one treatment cycle

None of the studies reported ongoing pregnancy rate per woman after one treatment cycle.

- Pregnancy rate per woman after one treatment cycle

The pregnancy rates after one insemination are higher for IUI, but the difference is not statistically significant (OR 2.62, 95\% CI 0.76 to 9.07: statistical heterogeneity $\mathrm{P}=0.46, \mathrm{I}^{2}=0 \%$ ).

- Ongoing pregnancy rate per woman after all cycles

None of the studies reported ongoing pregnancy rate per woman after all treatment cycles.

- Pregnancy rate per woman after all treatment cycles

The two included studies reported pregnancy rate per woman was an outcome. The pregnancy rate in the IUI group was 20 per 41 women compared with 5 per 35 women in the CI group. The difference is statistically significant higher, but with a wide confidence interval (OR 5.47, 95\% CI 1.95 to 15.35 :statistical heterogeneity $\left.\mathrm{P}=0.21, \mathrm{I}^{2}=37.4 \%\right)$.

- Adverse outcomes

One trial $(n=26)$ reported no miscarriages, ectopic pregnancy's or multiple pregnancies after one insemination. The adverse outcomes infection rate and adverse effects were not reported in the other study.

IUI versus CI in gonadotrophin-stimulated cycles with cryopreserved sperm

Two of the included studies compare IUI and CI in gonadotrophin-stimulated cycles with cryopreserved sperm in 131 women for a maximum of six cycles per woman. (Wainer 1995, Matorras 1996)

- Live birth rate per woman after all treatment cycles

Both included studies reported live birth as an outcome. IUI gave a statistically significant higher live birth rate (OR 2.07, 95\% CI 1.04 to 4.10 :statistical heterogeneity $\mathrm{P}=0.74, \mathrm{I}^{2}=0 \%$ ).

- Live birth rate per woman after one treatment cycle

None of the studies reported live birth rate per woman after one treatment cycle.

- Ongoing pregnancy rate per woman after one treatment cycle

None of the studies reported ongoing pregnancy rate per woman after one treatment cycle.

- Pregnancy rate per woman after one treatment cycle

One study reported pregnancy rate per woman after one treatment cycle. There were two pregnancies in the CI group $(n=20)$ and three pregnancies in the IUI group $(\mathrm{n}=23)(\mathrm{OR} 1.34,95 \% \mathrm{CI}$ 0.21 to 8.47$)$.

- Ongoing pregnancy rate per woman after all treatment cycles

None of the studies reported ongoing pregnancy rate per woman after all treatment cycles.

- Pregnancy rate per woman after all treatment cycles

Both included studies reported pregnancy rate as an outcome. IUI gave a statistically significant higher pregnancy rate (OR 2.72, 95\% CI 1.37 to 5.40: statistical heterogeneity $\mathrm{P}=0.92, \mathrm{I}^{2}=0 \%$ ).

- Adverse outcomes

Both trials reported miscarriage and multiple pregnancy rates per woman but the differences found were not significant. None of the studies reported ectopic pregnancies rate, infection rate or adverse effects rate per woman.

- Miscarriage rate per woman

Both included studies reported miscarriage rate as an outcome. In total there were 7 miscarriages. The difference between groups 
was not statistically significant (OR 3.92, 95\% CI 0.85 to 17.96 : statistical heterogeneity $\left.\mathrm{P}=0.78, \mathrm{I}^{2}=0 \%\right)$.

- Multiple pregnancy rate per woman

Both included studies reported multiple pregnancy as an outcome. There were 12 multiple pregnancies in the IUI group and five multiple pregnancies in the CI group. This difference in multiple pregnancy rate was not statistically significant (OR 2.19, 95\% CI 0.79 to 6.07 :statistical heterogeneity $\mathrm{P}=0.87, \mathrm{I}^{2}=0 \%$ ).

\section{ISCUSSION}

The aim of this systematic review was to assess the evidence on the comparative effectiveness of CI and IUI with donor sperm. Although ICSI has become an important treatment in male factor infertility, donor sperm insemination remains an option for some couples with azoospermia, a same sex relationship or for single women. IUI has come to replace CI in many centres as a result of clinical trials over the years. This review assessed the value of this change based on the results of randomised clinical trials.

\section{Summary of main results}

Few true randomised clinical trials were available. Comparisons could only be made with two interventions and a few outcomes could be pooled. In up to six cycles of insemination, in both clomiphene and gonadotrophin-stimulated cycles with cryopreserved sperm, live birth rates and pregnancy rates were higher using IUI. There was no evidence of significant differences for any of the adverse outcomes. No studies were included that inseminated with fresh sperm or in natural cycles. Therefore, there remains a gap in the evidence on these subjects.

\section{Quality of evidence}

\section{See Table 1}

The methodology of the included trials was of moderate quality. All studies performed randomisation, but in one trial the method used was unclear. The allocation was concealed in two trials and two trials did not state whether it was concealed or not. This could cause selection bias and an overestimation of the results (Daya 2003; Vail 2003).

One study reported couples that dropped out (Patton 1992), mostly because of protocol violation. No intention-to-treat analysis was performed but the drop-outs were equally distributed in both intervention groups. It is therefore unlikely that the dropouts affected the outcome of the trial in a major way. In the same study, the number of suboptimal cycles was unequally distributed and more CI than IUI couples had to receive clomiphene treatment. This may have favoured IUI in the trial and possibly in the metaanalysis. We were unable to perform an intention-to-treat analysis because we unable to retrieve additional data on the women who dropped out.

The blinding of the procedure is not mentioned in the studies but it would have been difficult to blind the insemination technique to the clinicians. Women may notice a difference because of the more invasive procedure of IUI. Because of these problems in the blinding procedure of the insemination technique, bias is a possibility but its effect is difficult to detect or assess.

The study populations in the trials were small and in three of the four included studies no power calculation was performed. In total we were able to pool results for 210 women of whom 26 women received an insemination only once. The odds ratios from the pooled data have wide confidence intervals because of this small number of women. The evidence found is, therefore, not strong and is imprecise.

\section{Potential biases in the review process}

It is a possibility that single women or the women of couples with the indication of azoospermia who were included in the studies were on average more fertile than women of couple with the indication oligospermia. Women with an oligospermic partner have a chance of conceiving a child naturally and, therefore, women with a good or high fertility may not need donor insemination. Women who have no male partner or have an azoospermic partner may have a better fertility on average and may be more likely to get pregnant with insemination. The two trials that used stimulated cycles with clomiphene included more azoospermic than oligospermic couples, but the distribution of the couples was unclear and, therefore, the effect on the outcomes as well (Patton 1992; Hurd 1993). Of the trials that stimulated cycles with gonadotrophin, one trial stated that azoospermic and oligospermic couples were equally randomised (Matorras 1996); Wainer 1995 only included sterile men and one couple with a genetic indication. It is not likely that the fertility of the couples influenced the outcomes in these trials.

The inclusion criteria can also influence the pregnancy outcomes of the studies. Couples with a longer history of infertility are more likely to have lower fertility. One study reported the duration of the subfertility of the included couples. On average women in the IUI group had a longer history of subfertility. But in spite of this disadvantage the IUI group had higher pregnancy rates.

Women who received previous treatment but did not conceive may also have a lower fertility. These characteristics are described in one study but it was not possible to assess if this biased the results.

The fecund ability of women declines with increasing age (Dunson 2004), which probably results in a lower overall pregnancy rate per cycle for intrauterine insemination with frozen donor sperm 
(Ferrara 2002). The woman's age is therefore an important determinant for the success rate of insemination. The women in the included studies were of a similar mean age, so age is not likely to have caused bias.

The characteristics of the sperm used for insemination may influence the success of the insemination. There is insufficient evidence to state that a superior sperm preparation technique exists (Boomsma 2004). The number of motile sperm used for the insemination differed between the studies, from 1.58 million post wash in Wainer to 43.7 million in Patton. The number of sperm used in the trials for either CI or IUI did not differ greatly. It is difficult to assess what the influence of the differences in sperm count may have been on the outcomes because of different ovulation stimulation regimes. But the numbers used in the studies for IUI are all greater than the suggested threshold of 0.8 to five million motile sperm after washing (van Weert 2004).

The optimal timing for IUI in gonadotrophin-stimulated cycles is between 32 hours and 38 hours after the hCG administration (Ragni 2004). Both Matorras and Wainer performed the IUI within this preferred time limit. The CI was performed twice at 12 and 36 to 38 hours after the hCG administration; an optimal timing for $\mathrm{CI}$ is not known. It is possible that the double cervical insemination favoured CI, but IUI still resulted in a higher live birth and pregnancy rate.

The optimal timing for IUI or CI in clomiphene-stimulated cycles is not clear. Both studies performed the inseminations at the same time (Patton 1992; Hurd 1993) and therefore do not give clinical heterogeneity or bias. It is possible that CI and IUI are best performed at different times after the LH surge for optimal results. The timing of $\mathrm{LH}+1$ can bias results towards either IUI or CI.

In contrast with IUI, the success of CI may depend upon the state of the cervical mucus. The optimal state of mucus may be only present for a short period of time. None of the studies evaluated the state of the mucus before the insemination, which could result in suboptimal conditions for CI and, as a result, lower pregnancy rates.

\section{Agreements and disagreements with other studies}

The overall 2002 pregnancy rates in Europe for IUI are 16.6\% per initiated cycle, ranging between $6.7 \%$ and $37.5 \%$ (ESHRE 2006). This is the average pregnancy rate for women under 40 years irrespective of the ovulation induction method or number of previous inseminations. The pregnancy rates per cycle for most of the included studies were higher, namely 23\% (Patton 1992), 20\% (Wainer 1995) and 24\% (Matorras 1996). Only Hurd 1993 had a lower pregnancy rate per cycle, of $8 \%$, but this is the pregnancy rate of the first insemination cycle only.

The higher multiple pregnancy rates for IUI reported in this review, although not significant, are in agreement with Tur 1997. Tur performed a retrospective non-random analysis of insemination techniques using donor sperm and found a significantly higher multiple pregnancy rate in IUI with gonadotrophin stimulation in comparison to CI with gonadotrophin stimulation.

\section{Discussion of crossover trials}

Unfortunately we had to exclude most of the potentially eligible trials because they had a crossover design without separate precrossover data being available. The crossover design is not suitable for fertility research and the overall methodology quality of the studies was also poor in other respects. Two studies randomised by alternation (Peters 1993; Carroll 2001) and in four other trials it was unclear (Patton 1990; Ract 1992; Alexander 1994; Pistorius 1996). There was no mention of concealment of allocation in any of the studies.

In spite of these methodological problems it would be a loss of information not to mention the results in this review. The crossover studies included women with natural, clomiphene or gonadotrophin-stimulated cycles. A total of 1171 cycles were performed with cryopreserved sperm and results are presented in Figure 1. Two studies were excluded from the table because they allocated by alternation (Peters 1993; Carroll 2001). Overall the studies showed a higher pregnancy rate per cycle with IUI (11.2\%) than CI (5.6\%). No statistically significant differences were found in miscarriage rates. These results are comparable with the findings of this review, that IUI is a more effective than CI with cryopreserved sperm. 
Figure I. Table 2.

\begin{tabular}{|c|c|c|c|c|c|c|c|c|}
\hline \multirow[t]{2}{*}{ Study } & \multicolumn{2}{|c|}{$\begin{array}{l}\text { Pregnancy rate } \\
\text { after one cycle }\end{array}$} & \multicolumn{2}{|c|}{$\begin{array}{l}\text { Pregnancy rate after all } \\
\text { cycles }\end{array}$} & \multicolumn{2}{|c|}{$\begin{array}{l}\text { Multiple } \\
\text { pregnancy rate } \\
\text { percycle }\end{array}$} & \multicolumn{2}{|c|}{$\begin{array}{l}\text { Miscarriagerate per } \\
\text { cycle }\end{array}$} \\
\hline & $\mathbf{C I}$ & IUI & CI & IUI & CI & IUI & CI & IUI \\
\hline \multicolumn{9}{|c|}{ Unknownstimulation } \\
\hline Alexander 1994 & & & $\begin{array}{l}4.2 \% \\
(7 / 166)\end{array}$ & $7 \%(13 / 185)$ & & & & \\
\hline \multicolumn{9}{|l|}{ Naturalcycles } \\
\hline Williams 1995 & & & $9.3 \%(4 / 43)$ & $\begin{array}{l}14.3 \% \\
(6 / 42) \\
\end{array}$ & & & & \\
\hline Pistorius 1996 & & & $6.4 \%(2 / 31)$ & $\begin{array}{l}20.5 \% \\
(7 / 34)\end{array}$ & & & & \\
\hline \multicolumn{9}{|c|}{ Clomiphene stimulated cycles } \\
\hline Williams 1995 & & & $12 \%(3 / 25)$ & $\begin{array}{l}22.6 \% \\
(7 / 31)\end{array}$ & & & $\begin{array}{l}3.8 \% \\
(3 / 78)\end{array}$ & $\begin{array}{l}1.4 \% \\
(1 / 73)\end{array}$ \\
\hline Pistorius 1996 & & & $0.0 \%(0 / 27)$ & $20 \%(4 / 20)$ & & & & \\
\hline \multicolumn{9}{|c|}{ Mixed natural and clomiphene stimulated cycles } \\
\hline Byrd 1990 & & & $3.9 \%(9 / 229)$ & $\begin{array}{l}9.7 \% \\
(23 / 238)\end{array}$ & & & $\begin{array}{l}0.04 \% \\
(1 / 229)\end{array}$ & $\begin{array}{l}1.7 \% \\
(4 / 238)\end{array}$ \\
\hline \multicolumn{9}{|c|}{ Gonadotrophin stimulated cycles } \\
\hline Ract 1992 & & & $13.7 \%(7 / 51)$ & $\begin{array}{l}14.3 \% \\
(7 / 49) \\
\end{array}$ & & & & \\
\hline Total & & & $\begin{array}{l}5.6 \% \\
(32 / 572)\end{array}$ & $\begin{array}{l}11.2 \% \\
(67 / 599)\end{array}$ & & & $\begin{array}{l}1.3 \% \\
(4 / 307)\end{array}$ & $\begin{array}{l}1.6 \% \\
(5 / 311)\end{array}$ \\
\hline
\end{tabular}

The one study that used fresh sperm found no statistically significant difference in pregnancy rate per cycle between IUI and CI (Patton 1990). The results are shown in Figure 2

Figure 2. Table 3.

\begin{tabular}{|c|c|c|c|c|c|c|c|c|}
\hline \multirow[t]{2}{*}{ Study } & \multicolumn{2}{|c|}{$\begin{array}{l}\text { Pregnancy rate } \\
\text { after one cycle }\end{array}$} & \multicolumn{2}{|c|}{$\begin{array}{l}\text { Pregnancy rate after all } \\
\text { cycles }\end{array}$} & \multicolumn{2}{|c|}{$\begin{array}{l}\text { Multiple } \\
\text { pregnancy rate } \\
\text { percycle }\end{array}$} & \multicolumn{2}{|c|}{$\begin{array}{l}\text { Miscarriage rate per } \\
\text { cycle }\end{array}$} \\
\hline & CI & IUI & CI & IUI & CI & IUI & CI & IUI \\
\hline \multicolumn{9}{|l|}{ Fresh sperm } \\
\hline Patton 1990 & & & $\begin{array}{l}18.5 \% \\
(5 / 27)\end{array}$ & $14.8 \%(4 / 27)$ & & & & \\
\hline
\end{tabular}

\section{A U THORS, CONCLUSIONS Implications for practice}

In clinical practice, IUI is a widely used method to overcome fertility problems. CI is potentially a less invasive technique and could be useful if shown to have similar effectiveness to IUI. However this review provides evidence, albeit from a small number of trials, that IUI improves pregnancy outcomes compared with CI with no evidence of increased risk of adverse effects. Therefore, no change in policy for IUI is recommended.

\section{Implications for research}

As most eligible trials for the review had to be excluded because of their crossover design, it is important that further fertility research 
on this subject should be performed with a parallel study design.

It is unlikely that further studies comparing CI with IUI will be undertaken in the future but if future studies are contemplated the following issues should be carefully addressed:

- parallel design

- rates per women

- allocation concealment
- randomisation

\section{ACKNOW LEDGEMENTS}

Thanks to Paul O' Brien and Patrick Vanderkerckhove who were the authors of the original review, first published in 1998. Thanks to Andy Vail for his statistical guidance. Thanks to Roberto Matorras and William Hurd for providing us additional information from their studies.

\section{R E F E R E N C E S}

\section{References to studies included in this review}

Hurd 1993 \{published and unpublished data\}

Hurd WW, Randolph JF Jr, Ansbacher R, Menge AC, Ohl DA, Brown AN. Comparison of intracervical, intrauterine, and intratubal techniques for donor insemination. Fertility and Sterility 1993;59(2):339-42.

Matorras 1996 \{published data only\}

Matorras R, Gorostiaga A, Diez J, Corcostegui B, Pijoan J, Ramon O, Rodriguez-Escudero FJ. Intrauterine insemination with frozen sperm increases pregnancy rates in donor insemination cycles under gonadotropin stimulation. Fertility and Sterility 1996;65:620-5.

Patton 1992 \{published data only\}

Patton PE, Burry KA, Thurmond A, Novy MJ, Wolf DP. Intrauterine insemination outperforms intracervical insemination in a randomized, controlled study with frozen, donor semen. Fertility and Sterility 1992;57(3):559-64.

Wainer 1995 \{published data only\}

Wainer R, Merlet F, Ducot B, Bailly M, Tribalat S, Lombroso R. Prospective randomized comparison of intrauterine and intracervical insemination with donor spermatozoa. Human Reproduction 1995;10(11):2919-22.

\section{References to studies excluded from this review}

Alexander 1994 \{published data only\}

Alexander C, Lafferty A, Smith C, Mc Nally W, Ralston C, Jamison $\mathrm{M}$, et al.Treatment of male infertility: a comparison of DI and IUID. Abstracts of 2nd International Meeting of the BFS. Glasgow, 1994.

Byrd 1990 \{published data only\}

Byrd W, Bradshaw K, Carr B, Edman C, Odom J, Ackerman G. A prospective randomized study of pregnancy rates following intrauterine and intracervical insemination using frozen donor sperm. Fertility and Sterility 1990;53:521-7.

Carroll 2001 \{published data only\}

Carroll N, Palmer JR. A comparison of intrauterine versus intracervical insemination in fertile single women. Fertility and Sterility 2001;75(4):656-660.
Le Lannou 1989 \{published data only\}

Le Lannou D, Laroche M, Ommi-Bie N, Gastard E, Gueho A, Sevene L, et al.Interets des inseminations intra-uterines dans un programme d'IAD. Contraception Fertilite Sexualite 1989;17:665-6.

Patton 1990 \{published data only\} Patton P, Burry K, Novy M, Wold D. A comparative evaluation of intracervical and intrauterine routes in donor therapeutic insemination. Human Reproduction 1990;5: 263-5.

Peters 1993 \{published data only\} Peters A, Hecht B, Wentz A, Jeyendran R. Comparison of the methods of artificial insemination on the incidence of conception in single unmarried women. Fertility and Sterility 1993;59:121-4.

Pistorius 1996 \{published data only\} Pistorius LR, Kruger TF, De Villier A, van der Merwe JP. A comparative study using prepared and unprepared frozen semen for donor insemination. Archives of Andrology 1993; 36:81-6.

Ract 1992 \{published data only\}

Ract V, Barthelemy C, Lanoue C, Lecomte C, Lansac J, Royere D. Comparaison entre inseminations intracervicales et intra-uterines en IAD au-dela du Ge cycles. Contraception Fertilite Sexualite 1992;20:799-800.

Urry 1988 \{published data only\}

Urry R, Middleton R, Jones K, Poulson M, Worley R, Keye W. Artificial insemination: a comparison of pregnancy rates with intrauterine versus cervical insemination and washed sperm versus swim-up sperm preparations. Fertility and Sterility 1988;49:1036-8.

Walker 1993 \{published and unpublished data\} Walker D, Kennedy C, Clarke T, Skelton J. A study to compare transcervical donor insemination and superovulated donor intra-uterine insemination. Human Reproduction 1993;8(Suppl 1):151.

Williams 1995 \{published data only\} Williams D, Moley K, Cholewa C, Odem R, Willand J, Gast M. Does intrauterine insemination offer an advantage 
to cervical cap insemination in a donor insemination program?. Fertility and Sterility 1995;63:295-8.

\section{Additional references}

Boomsma 2004

Boomsma CM, Heineman MJ, Cohlen BJ, Farquhar C. Semen preperation techniques for intrauterine insemination. Cochrane Database of Systematic Reviews 2004, Issue 3.

\section{British 1999}

British Andrology Society. British Andrology Society guidelines for the screening of semen donors for donor insemination. Human Reproduction 1999;14(7):1823-6.

Daya 2003

Daya S. Pitfalls in the design and analysis of efficacy trials in subfertility. Human Reproduction 2003;18(5):1005-9.

\section{Delvigne 2002}

Delvigne A, Rozenberg S. Epidemiology and prevention of ovarian hyperstimulation. Human Reproduction 2002;8(6): 559-77.

\section{Dunson 2004}

Dunson DB, Baird DD, Colombo B. Increased infertility with age in men and women. The American College of Obstetricians and Gynecologist 2004;103(1):51-6.

\section{ESHRE 2006}

ESHRE Central Office, Grimbergen, Belgium. Assisted reproductive technology in Europe, 2002. Results generated from European registers by ESHRE. Human Reproduction 2006;21(7):1680-97.

Fauser 2005

Fauser BCJM, Devroey P, Macklon NS. Multiple birth resulting from ovarian stimulation for subfertility treatment. Lancet 2005;365:1807-16.

\section{Ferrara 2002}

Ferrare I, Balet R, Grudzinskas JG. Intrauterine insemination with frozen donor sperm. Pregnancy outcome in relation to age and ovarian stimulation regime. Human Reproduction 2002;17(9):2320-24.

\section{Gorrill 2003}

Gorrill MJ, Burry KA, Patton E. Pregnancy outcomes using donor sperm insemination after failed in vitro fertilization with intracytoplasmic sperm injection cycles in couples with complex infertility disorders. Fertility and Sterility 2003;80 (4):936-8.

\section{Higgins 2006}

Higgins JP, Green S, editors. Cochrane Handbook for systematic reviews of interventions, version 4.2.5 (updated May 2005). www.cochrane.org/resources/handbook/ hbook.htm (accessed 07 September 2006).
Lechmacher 1991

Lechmacher W. Analysis of the crossover design in the presence of residual effects. Statistics in Medicine 1991;10: 891-9.

\section{Ragni 2004}

Ragni G, Somigliana E, Vegetti W. Timing of intrauterine insemination: where are we?. Fertility and Sterility 2004;82 (1):25-6.

\section{Ripps 1994}

Ripps BA, Minhas BS, Carson SA, Buster JE. Intrauterine insemination in fertile women delivers larger numbers of sperm to the peritoneal fluid than intracervical insemination. Fertility and Sterility 1994;61(2):398-400.

\section{Sharma 1997}

Sharma RK, Vemulapalli S, Kohn S, Agarwal A. Effect of centrifuge speed, refrigeration medium, and sperm washing medium on crypreserved sperm quality after thawing. Archives of Andrology 1997;39:33-8.

\section{Subak 1992}

Subak LL, Adamson D, Boltz NL. Therapeutic donor insemination: A prospective randomized trial of fresh versus frozen sperm. American Journal of Obstetrics \& Gynecology 1992; June:1597-04.

Taylor 2003

Taylor A. ABC of subfertility, Extent of the problem. BMJ 2003;327:434-6.

\section{Tur 1997}

Tur R, Buxaderas CH, Martinez F, Busquets A, Coroleu $\mathrm{B}$, Barri PN. Comparison of the role of cervical and intrauterine insemination techniques on the incidence of multiple pregnancy after artificial insemination with donor sperm. Journal of Assisted Reproduction and Genetics 1997; 14(5):250-53.

Vail 2003

Vail A, Gardener E. Common statistical errors in the design and analyis of subfertility trials. Human Reproduction 2003; 18(5):1000-4.

van Weert 2004

van Weert J-M, Repping S, Van Voorhis BJ, van der Veen F, Bossuyt PMM, Mol BWJ. Performance of the postwash total motile sperm count as a predictor of pregnancy at the time of intrauterine inseminaiton: a meta-analysis. Fertility and Sterility 2004;82(3):612-20.

\section{References to other published versions of this review}

\section{O'Brien}

O'Brien P, Vandekerckhove P. Intra-uterine versus cervical insemination of donor sperm for subfertility. Cochrane Database of Systematic Reviews 1998, Issue 4.

* Indicates the major publication for the study 


\section{CHARACTERISTICS OF STUDIES}

\section{Characteristics of included studies [ordered by study ID]}

\section{Hurd 1993}

\begin{tabular}{|c|c|c|}
\hline Methods & \multicolumn{2}{|c|}{$\begin{array}{l}\text { Randomisation: random number lists } \\
\text { Allocation concealment: Using opaque consecutively numbered envelopes } \\
\text { Study design: crossover } \\
\text { Number of women randomised: } 41 \\
\text { Number of dropouts none }\end{array}$} \\
\hline Participants & \multicolumn{2}{|c|}{$\begin{array}{l}\text { Participants: pre-crossover; CI } 13 \text { women; IUI } 13 \text { women; transcervical intratubal insemination combined } \\
\text { with IUI } 15 \text { women } \\
\text { Indication: couples with azoospermia, severe oligospermia and single women } \\
\text { Study of couples: Basal Body Temperature, hysterosalpingography. } 15 \text { women also had laparoscopy, and } \\
7 \text { of those had laser treatment for tubal adhesions or endometriosis grade I or II } \\
\text { Criteria: excluded: not corrected ovulatory dysfunction } \\
\text { Age: not stated per intervention group (all women; } 23+/-4 \text { years) } \\
\text { Duration of infertility: not stated } \\
\text { Previous treatment: not stated }\end{array}$} \\
\hline Interventions & \multicolumn{2}{|c|}{$\begin{array}{l}\text { Ovulation induction method: } 23 \text { women of } 41 \text { had clomiphene -corrected cycles } \\
\text { Timing of insemination: single insemination on } \mathrm{LH}+1 \text { day }\end{array}$} \\
\hline Outcomes & \multicolumn{2}{|c|}{$\begin{array}{l}\text { Primary outcome: Live birth } \\
\text { Secondary outcome: Pregnancy rate } \\
\text { Adverse outcome: Miscarriage rate, Multiple pregnancy rate, Ectopic pregnancy rate }\end{array}$} \\
\hline Notes & \multicolumn{2}{|c|}{$\begin{array}{l}\text { A third treatment in this three-way study was transcervical intratubal insemination combined with IUI } \\
\text { Pregnancy defined by serum hCG + ultrasound (gestation sac) } \\
\text { Donor sperm was purchased from International Cryogenics }\end{array}$} \\
\hline \multicolumn{3}{|l|}{ Risk of bias } \\
\hline Item & Authors' judgement & Description \\
\hline Allocation concealment? & Yes & A - Adequate \\
\hline
\end{tabular}

\section{Matorras 1996}

Methods

Randomisation: random number table

Allocation concealment: Using opaque consecutively numbered envelopes

Study design: paralel

Number of women randomised: 88

Number of dropouts: none 


\begin{tabular}{|c|c|c|}
\hline Participants & \multicolumn{2}{|c|}{$\begin{array}{l}\text { Participants: } 41 \mathrm{CI} \text {; } 47 \text { IUI } \\
\text { Indication: couples with male infertility; stated as a sperm count of }<1,5 \text { X } 106 \text { motile sperm after Percoll } \\
\text { preparation } \\
\text { Study of couples:endometrial biopsy, determination of P and PRL, hysterosalpingography and sperm } \\
\text { analysis } \\
\text { Criteria: inclusion: infertility history of }>2 \text { years, at least one patent tube, women's age }<40 \text { years, } \\
\text { an abnormal sperm analysis according to WHO criteria and }<1.5 \text { million motile sperm after Percoll } \\
\text { preparation } \\
\text { Age: CI } 31.89+/-3.71 \text { years } \\
\text { IUI } 30.78+/-3.71 \text { years } \\
\text { Duration of infertility: CI; } 5.97+/-3.13 \text { years } \\
\text { IUI; } 7.81+/-3.75 \text { years } \\
\text { Previous treatment: not stated } \\
\text { Notes: CI; } 48.78 \% \text { of women with normal infertility studies } \\
\text { IUI; } 59.57 \% \text { of women with normal infertility studies }\end{array}$} \\
\hline Interventions & \multicolumn{2}{|c|}{$\begin{array}{l}\text { Ovulation induction method: gonadotrophin- stimulated cycles in both groups } \\
\text { Timing of insemination: CI; LH+ } 12 \text { and }+36 \text { hours } \\
\text { IUI; LH+ } 36 \text { hours } \\
\text { A maximum of } 6 \text { insemination cycles }\end{array}$} \\
\hline Outcomes & \multicolumn{2}{|c|}{$\begin{array}{l}\text { Primary outcome: Live birth per woman after all cycles } \\
\text { Secondary outcome: Pregnancy rate per woman after all cycles } \\
\text { Adverse outcome: Miscarriage rate, Multiple pregnancy rate }\end{array}$} \\
\hline Notes & \multicolumn{2}{|c|}{ Pregnancy defined by the visualisation of a gestational sac at 6 th to 7 th week of amenorrhoea } \\
\hline \multicolumn{3}{|l|}{ Risk of bias } \\
\hline Item & Authors' judgement & Description \\
\hline Allocation concealment? & Yes & A - Adequate \\
\hline
\end{tabular}

Patton 1992

Methods

Randomisation: Randomised, method unclear

Allocation concealment: unclear (B)

Study design: parallel

Number of women randomised: 69 women

Number of dropouts: 9 CI dropouts and 10 ICI dropouts; 7 women dropped out before the first insemination; 12 were eliminated from analyses for the following reasons: more than a single route of insemination (4), more than one insemination per cycle (2), uterine structural anomalies (4), gonadotropin use (2)

Participants

Participants: CI 22 women

IUI 28 women

Indication: couples with azoospermia, severe oligospermia and single women

Study of couples: Pre-insemination screening included basal body temperature, urinary LH assay, hysterosalpingography in women with historical risk 
Patton 1992 (Continued)

Criteria: excluding; women with abnormal hysterosalpingogram

Age: IUI $30.7+/-5$

ICI $32.0+/-5$

Duration of infertility: not stated

Previous treatment: not stated

Interventions

Ovulation induction method: abnormalities in ovulatory function were treated with clomiphene citrate.

ICI; 13 women with suboptimal cycles, 8 optimal after treatment.

IUI; 6 women with suboptimal cycles, 6 received treatment.

Timing of insemination: Single insemination on $\mathrm{LH}+1$ day

Notes: A maximum of six inseminations per woman

\begin{tabular}{l|l} 
Outcomes & $\begin{array}{l}\text { Primary outcome: } \\
\text { Secondary outcome: Pregnancy rate per woman after one cycle, pregnancy rate per woman after all cycles } \\
\text { Adverse outcome: }\end{array}$ \\
\hline Notes & $\begin{array}{l}\text { Intention to treat analyses is not stated } \\
\text { Pregnancies were confirmed by standard serum assays of human chorionic gonadotropin and ultrasound } \\
\text { evidence of a gestational sac. } \\
\text { Sperm donors were recruited from the medical community. }\end{array}$ \\
\hline
\end{tabular}

Risk of bias

\begin{tabular}{lll}
\hline Item & Authors' judgement & Description \\
\hline Allocation concealment? & Unclear & B - Unclear \\
\hline
\end{tabular}

Wainer 1995

Methods

Randomisation: randomised list

Allocation concealment: unclear

Study design: parallel

Number of women randomised: 43

Number of dropouts: not stated

Participants

Participants: CI 20; IUI 23

Indication: couples with sterile men and one couple with a genetic indication

Study of couples:analysis of the cervical mucus, hysterosalpingography, hormonal screening, basal body temperature chart

Criteria: Women had no other infertility factors accept slight ovulation dysfunction

Age: CI $30+/-0.3$ years

IUI $31+/-0.4$ years

Duration of infertility: not stated

Previous treatment: CI; 1 birth after CI

IUI; 1 birth and 1 miscarriage after CI

Notes: CI; 1 miscarriage, 1 abortion

IUI; 1 miscarriage, 1 abortion

Cervical insemination versus intra-uterine insemination of donor sperm for subfertility (Review) 


\section{Wainer 1995 (Continued)}

\begin{tabular}{|c|c|c|}
\hline Interventions & \multicolumn{2}{|c|}{$\begin{array}{l}\text { Ovulation induction method: Women with slight ovulation dysfunction were gonadotrophin- stimulated } \\
\text { Timing of insemination: CI; } 12+/-4 \text { hours and } 38+/-4 \text { hours after HCG injection } \\
\text { IUI; } 38+/-4 \text { hours after HCG injection } \\
\text { Notes: Some of the first IC inseminations had only } 1 \text { insemination. Women were inseminated for two } \\
\text { successive menstrual cycles followed by a rest cycle to a maximum of six inseminations }\end{array}$} \\
\hline Outcomes & \multicolumn{2}{|c|}{$\begin{array}{l}\text { Primary outcome: Live birth rate per woman after all cycles } \\
\text { Secondary outcome: Pregnancy rate per woman after one cycle, pregnancy rate per woman after all cycles } \\
\text { Adverse outcome: Multiple pregnancy, Miscarriage rate }\end{array}$} \\
\hline Notes & \multicolumn{2}{|c|}{$\begin{array}{l}\text { Pregnancy defined as being visible by ultrasound } \\
\text { Donor sperm was supplied by three different centres }\end{array}$} \\
\hline \multicolumn{3}{|l|}{ Risk of bias } \\
\hline Item & Authors' judgement & Description \\
\hline Allocation concealment? & No & C - Inadequate \\
\hline
\end{tabular}

Characteristics of excluded studies [ordered by study ID]

\begin{tabular}{|c|c|}
\hline Study & Reason for exclusion \\
\hline Alexander 1994 & $\begin{array}{l}\text { 1.Crossover } \\
\text { 2.Appeared as an abstract only }\end{array}$ \\
\hline Byrd 1990 & $\begin{array}{l}\text { 1.Crossover; no pre-crossover data available } \\
\text { 2.Allocation concealment not stated }\end{array}$ \\
\hline Carroll 2001 & $\begin{array}{l}\text { 1. Randomisation by alternation } \\
\text { 2.Crossover; no pre-crossover data available } \\
\text { 3.Allocation concealment not stated }\end{array}$ \\
\hline Le Lannou 1989 & $\begin{array}{l}\text { 1.Pseudo randomised } \\
\text { 2.No distinction between natural and hyperstimulated cycles in control group }\end{array}$ \\
\hline Patton 1990 & $\begin{array}{l}\text { 1.Crossover; no pre-crossover data available } \\
\text { 2.Allocation concealment not stated } \\
\text { 3.Randomisation method not stated }\end{array}$ \\
\hline Peters 1993 & $\begin{array}{l}\text { 1.Crossover; no pre-crossover data available } \\
\text { 2.Allocation concealment not stated } \\
\text { 3.Randomisation by alternation }\end{array}$ \\
\hline
\end{tabular}


(Continued)

Pistorius 1996 1.Crossover; no pre-crossover data available

2.Allocation concealment not stated

3.Randomisation method not stated

Ract 1992 1.Crossover; no pre-crossover data available

2.Allocation concealment not stated

3.Randomisation method not stated

Urry 1988 1.Crossover; no pre-crossover data available

2.Allocation concealment not stated

3.Randomisation method not stated

Walker 1993 1. Stated to be RCT but all patients received CI in the first treatment cycle

2. CI cycles which some patients had undergone before the trial were included in the results

3. Hyperstimulated cycles versus natural cycles

Williams 1995 1.Crossover; no pre-crossover data available

2. Allocation concealment not stated 
DATA ANDANALYSES

Comparison 1. IUI versus CI in stimulated cycles with cryopreserved sperm

\begin{tabular}{|c|c|c|c|c|}
\hline Outcome or subgroup title & $\begin{array}{l}\text { No. of } \\
\text { studies }\end{array}$ & $\begin{array}{c}\text { No. of } \\
\text { participants }\end{array}$ & Statistical method & Effect size \\
\hline $\begin{array}{l}1 \text { Live birth rate per woman after } \\
\text { all treatment cycles }\end{array}$ & 3 & 157 & Peto Odds Ratio (Peto, Fixed, 95\% CI) & $1.98[1.02,3.86]$ \\
\hline $\begin{array}{l}1.1 \mathrm{IUI} \text { versus } \mathrm{CI} \text { in } \\
\text { clomiphene-stimulated cycles }\end{array}$ & 1 & 26 & Peto Odds Ratio (Peto, Fixed, 95\% CI) & $1.0[0.06,16.93]$ \\
\hline $\begin{array}{l}1.2 \text { IUI versus } \mathrm{CI} \text { in } \\
\text { gonadotrophin-stimulated } \\
\text { cycles }\end{array}$ & 2 & 131 & Peto Odds Ratio (Peto, Fixed, 95\% CI) & $2.07[1.04,4.10]$ \\
\hline $\begin{array}{l}2 \text { Live birth rate per woman after } \\
\text { one treatment cycle }\end{array}$ & 1 & 26 & Peto Odds Ratio (Peto, Fixed, 95\% CI) & $1.0[0.06,16.93]$ \\
\hline $\begin{array}{l}2.1 \text { IUI versus CI in } \\
\text { clomiphene-stimulated cycles }\end{array}$ & 1 & 26 & Peto Odds Ratio (Peto, Fixed, 95\% CI) & $1.0[0.06,16.93]$ \\
\hline $\begin{array}{l}2.2 \text { IUI versus CI in } \\
\text { gonadotrophin-stimulated } \\
\text { cycles }\end{array}$ & 0 & 0 & Peto Odds Ratio (Peto, Fixed, 95\% CI) & Not estimable \\
\hline $\begin{array}{l}3 \text { Pregnancy rate per woman after } \\
\text { one treatment cycle }\end{array}$ & 3 & 119 & Peto Odds Ratio (Peto, Fixed, 95\% CI) & $2.12[0.76,5.95]$ \\
\hline $\begin{array}{l}3.1 \text { IUI versus CI in } \\
\text { clomiphene-stimulated cycles }\end{array}$ & 2 & 76 & Peto Odds Ratio (Peto, Fixed, 95\% CI) & $2.62[0.76,9.07]$ \\
\hline $\begin{array}{l}3.2 \text { IUI versus CI in } \\
\text { gonadotrophin-stimulated } \\
\text { cycles }\end{array}$ & 1 & 43 & Peto Odds Ratio (Peto, Fixed, 95\% CI) & $1.34[0.21,8.47]$ \\
\hline $\begin{array}{l}4 \text { Pregnancy rate per woman after } \\
\text { all treatment cycles }\end{array}$ & 4 & 207 & Peto Odds Ratio (Peto, Fixed, 95\% CI) & $3.37[1.90,5.96]$ \\
\hline $\begin{array}{l}\text { 4.1 IUI versus CI in } \\
\text { clomiphene-stimulated cycles }\end{array}$ & 2 & 76 & Peto Odds Ratio (Peto, Fixed, 95\% CI) & $5.47[1.95,15.35]$ \\
\hline $\begin{array}{l}4.2 \text { IUI versus CI in } \\
\text { gonadotrophin stimulated } \\
\text { cycles }\end{array}$ & 2 & 131 & Peto Odds Ratio (Peto, Fixed, 95\% CI) & $2.72[1.37,5.40]$ \\
\hline 5 Miscarriage rate per woman & 3 & 157 & Peto Odds Ratio (Peto, Fixed, 95\% CI) & $3.92[0.85,17.96]$ \\
\hline $\begin{array}{l}5.1 \text { IUI versus CI in } \\
\text { clomiphene-stimulated cycles }\end{array}$ & 1 & 26 & Peto Odds Ratio (Peto, Fixed, 95\% CI) & Not estimable \\
\hline $\begin{array}{l}5.2 \text { IUI versus CI in } \\
\text { gonadotrophin-stimulated } \\
\text { cycles }\end{array}$ & 2 & 131 & Peto Odds Ratio (Peto, Fixed, 95\% CI) & $3.92[0.85,17.96]$ \\
\hline $\begin{array}{l}6 \text { Multiple pregnancy rate per } \\
\text { woman }\end{array}$ & 3 & 157 & Peto Odds Ratio (Peto, Fixed, 95\% CI) & $2.19[0.79,6.07]$ \\
\hline $\begin{array}{l}\text { 6.1 IUI versus CI in } \\
\text { clomiphene-stimulated cycles }\end{array}$ & 1 & 26 & Peto Odds Ratio (Peto, Fixed, 95\% CI) & Not estimable \\
\hline $\begin{array}{l}6.2 \text { IUI versus CI in } \\
\text { gonadotrophin-stimulated } \\
\text { cycles }\end{array}$ & 2 & 131 & Peto Odds Ratio (Peto, Fixed, 95\% CI) & $2.19[0.79,6.07]$ \\
\hline
\end{tabular}

Cervical insemination versus intra-uterine insemination of donor sperm for subfertility (Review) 
Analysis I.I. Comparison I IUI versus $\mathrm{Cl}$ in stimulated cycles with cryopreserved sperm, Outcome I Live birth rate per woman after all treatment cycles.

Review: Cervical insemination versus intra-uterine insemination of donor sperm for subfertility

Comparison: I IUI versus $\mathrm{Cl}$ in stimulated cycles with cryopreserved sperm

Outcome: I Live birth rate per woman after all treatment cycles

$\begin{array}{lllr}\text { Peto } & \text { Peto } & \text { Pdds Ratio } & \text { Weight }\end{array}$

$\mathrm{n} / \mathrm{N} \quad \mathrm{n} / \mathrm{N} \quad$ Peto,Fixed,95\% Cl

Peto,Fixed,95\% Cl

I IUI versus $\mathrm{Cl}$ in clomiphene-stimulated cycles

Hurd 1993

$1 / 13$

$1 / 13$

Subtotal (95\% CI)

13

13

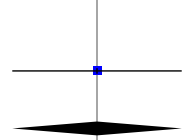

Total events: I (IUI), I (Cl)

Heterogeneity: not applicable

Test for overall effect: $Z=0.0(P=1.0)$

$2 \mathrm{IUI}$ versus $\mathrm{Cl}$ in gonadotrophin-stimulated cycles

$\begin{array}{lcr}\text { Matorras } 1996 & 26 / 47 & 16 / 41 \\ \text { Wainer 1995 } & 12 / 23 & 6 / 20\end{array}$

Wainer 1995

70

61

$30.7 \%$

$1.91[0.83,4.39]$

Subtotal (95\% CI)

$6 / 20$

Total events: 38 (IUI), 22 (Cl)

Heterogeneity: $\mathrm{Chi}^{2}=0.1 \mathrm{l}, \mathrm{df}=\mathrm{I}(\mathrm{P}=0.74) ; \mathrm{I}^{2}=0.0 \%$

Test for overall effect: $Z=2.08(P=0.038)$

Total (95\% CI)

83

\section{4}

$5.5 \%$

$1.00[0.06,16.93]$

Total events: 39 (IUI), $23(\mathrm{Cl})$

Heterogeneity: $\mathrm{Chi}^{2}=0.35, \mathrm{df}=2(\mathrm{P}=0.84) ; \mathrm{I}^{2}=0.0 \%$

Test for overall effect: $Z=2.02(P=0.044)$

Test for subgroup differences: $\mathrm{Chi}^{2}=0.24, \mathrm{df}=\mathrm{I}(\mathrm{P}=0.63), \mathrm{I}^{2}=0.0 \%$

$94.5 \%$

$2.43[0.73,8.09]$

$2.07[1.04,4.10]$

$100.0 \%$

$1.98[1.02,3.86]$ 
Analysis I.2. Comparison I IUI versus $\mathrm{Cl}$ in stimulated cycles with cryopreserved sperm, Outcome 2 Live birth rate per woman after one treatment cycle.

Review: Cervical insemination versus intra-uterine insemination of donor sperm for subfertility

Comparison: I IUI versus $\mathrm{Cl}$ in stimulated cycles with cryopreserved sperm

Outcome: 2 Live birth rate per woman after one treatment cycle

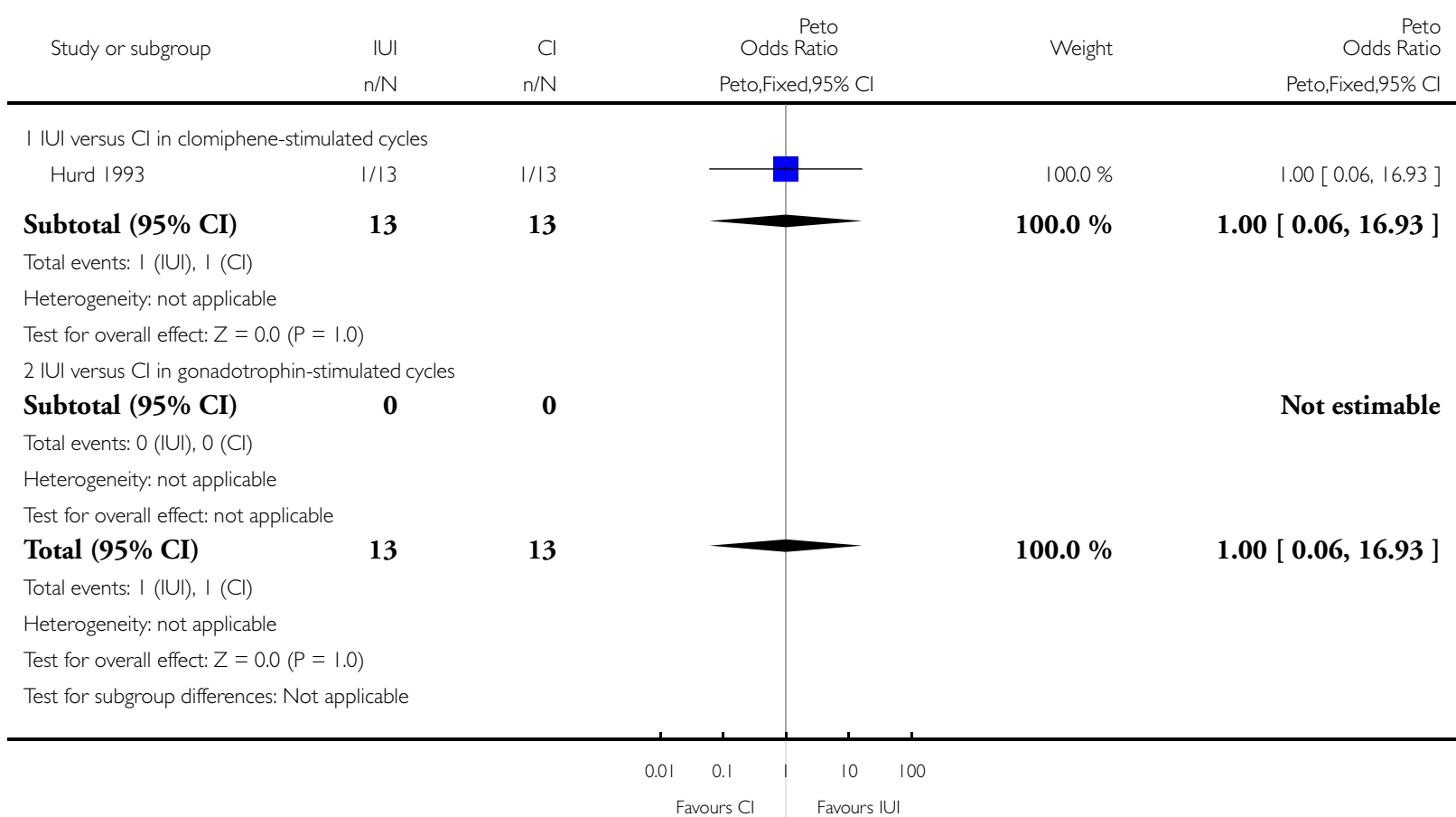


Analysis I.3. Comparison I IUI versus $\mathrm{CI}$ in stimulated cycles with cryopreserved sperm, Outcome 3 Pregnancy rate per woman after one treatment cycle.

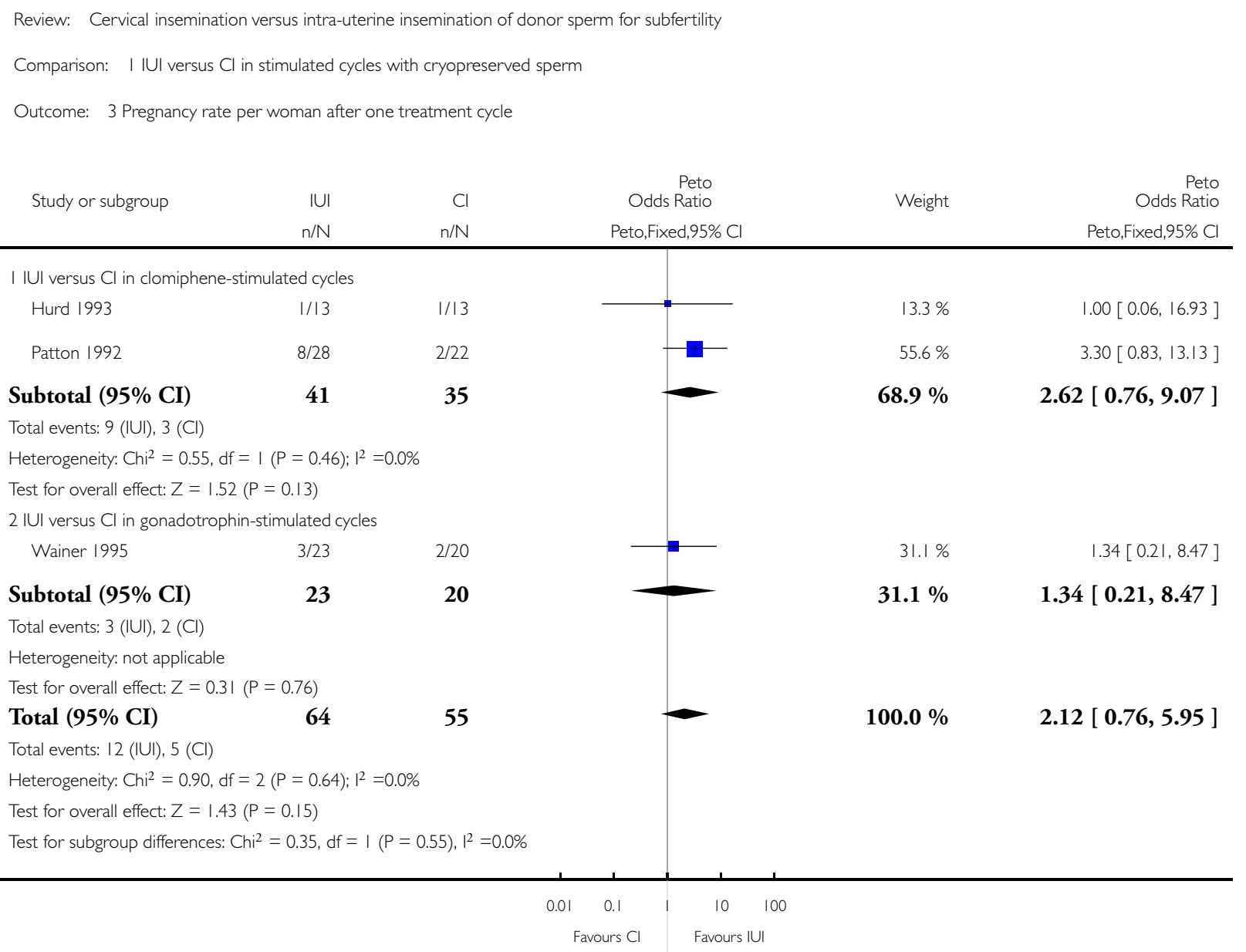


Analysis I.4. Comparison I IUI versus $\mathrm{Cl}$ in stimulated cycles with cryopreserved sperm, Outcome 4 Pregnancy rate per woman after all treatment cycles.

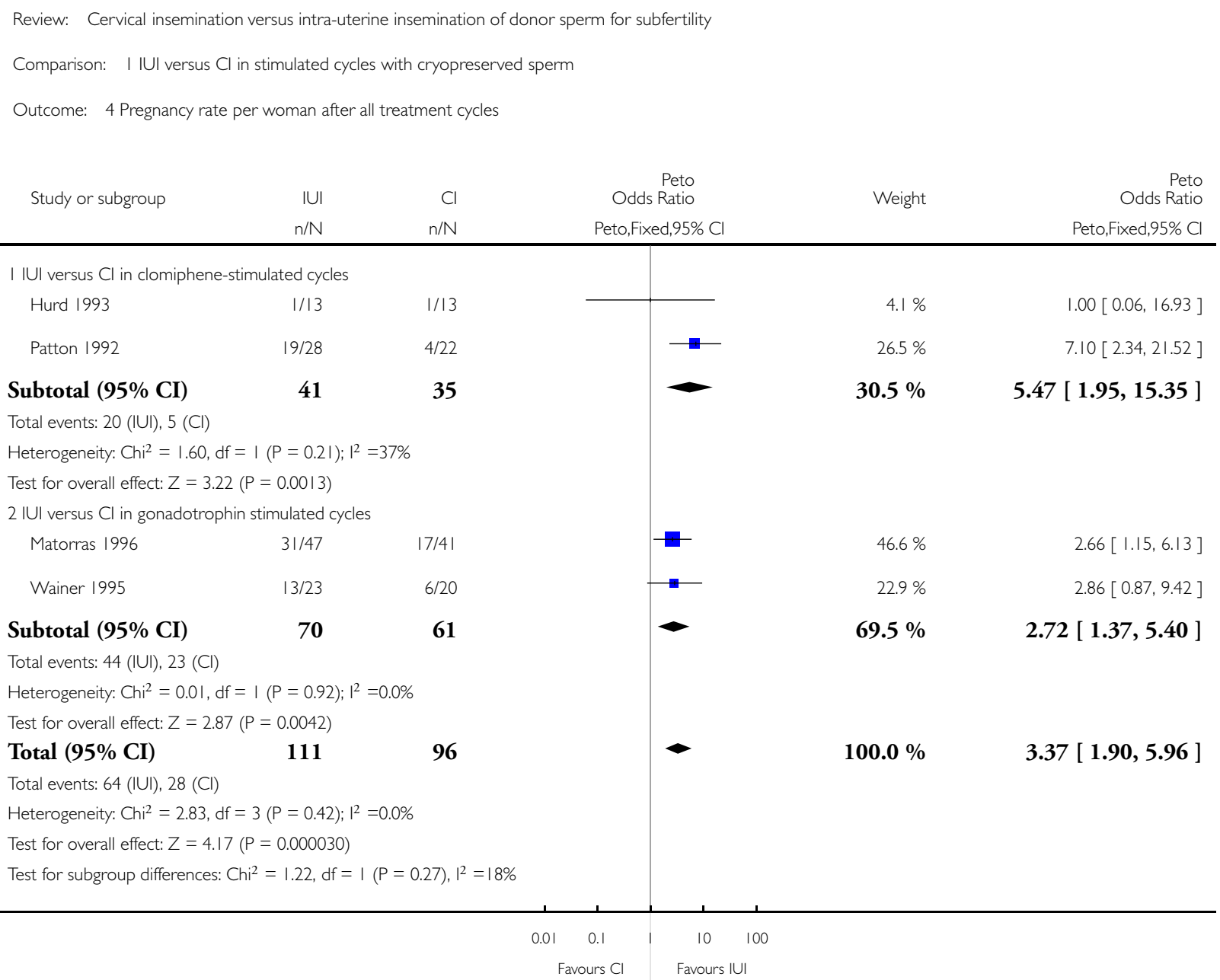


Analysis I.5. Comparison I IUI versus $\mathrm{Cl}$ in stimulated cycles with cryopreserved sperm, Outcome 5 Miscarriage rate per woman.

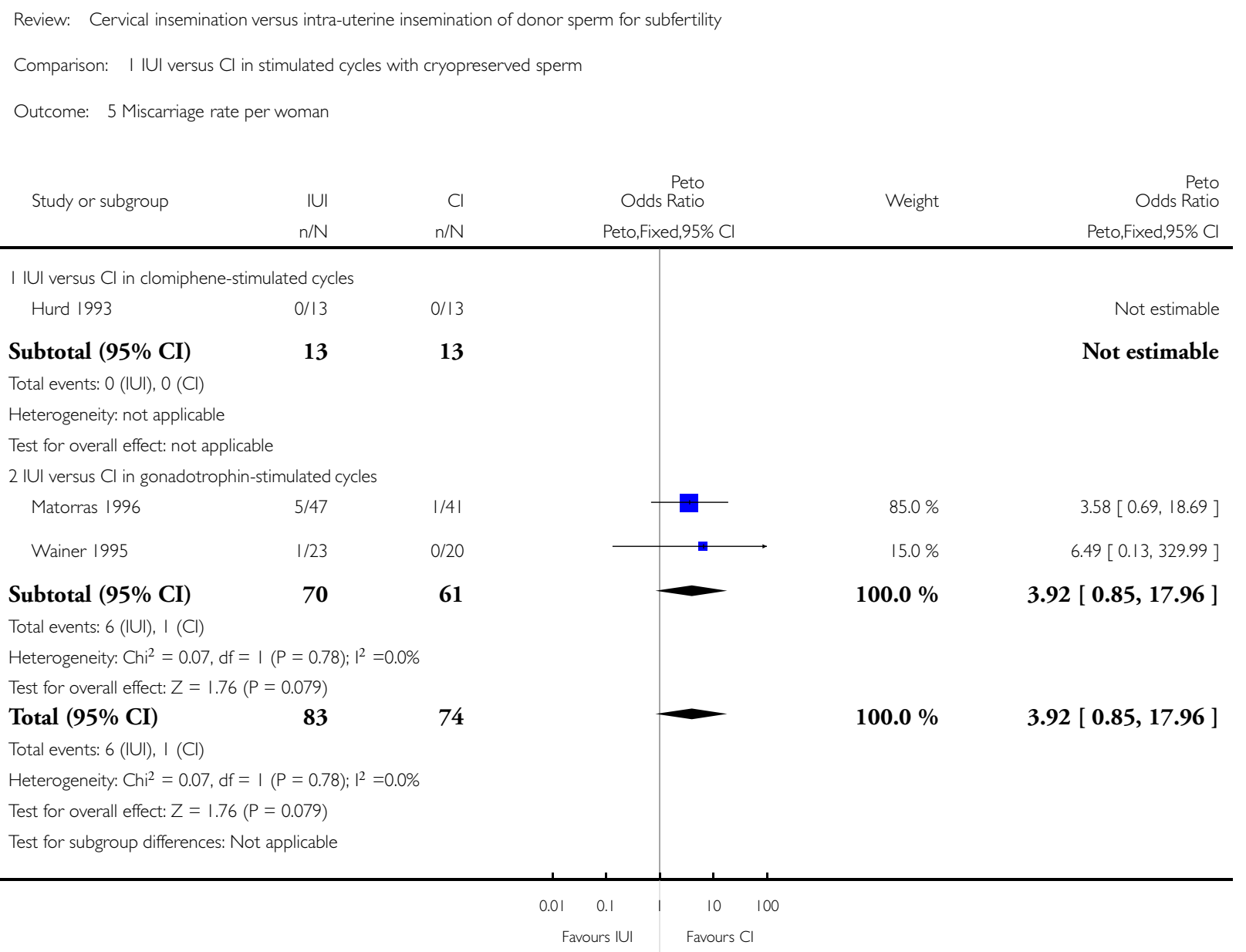




\section{Analysis I.6. Comparison I IUI versus CI in stimulated cycles with cryopreserved sperm, Outcome 6 Multiple pregnancy rate per woman.}

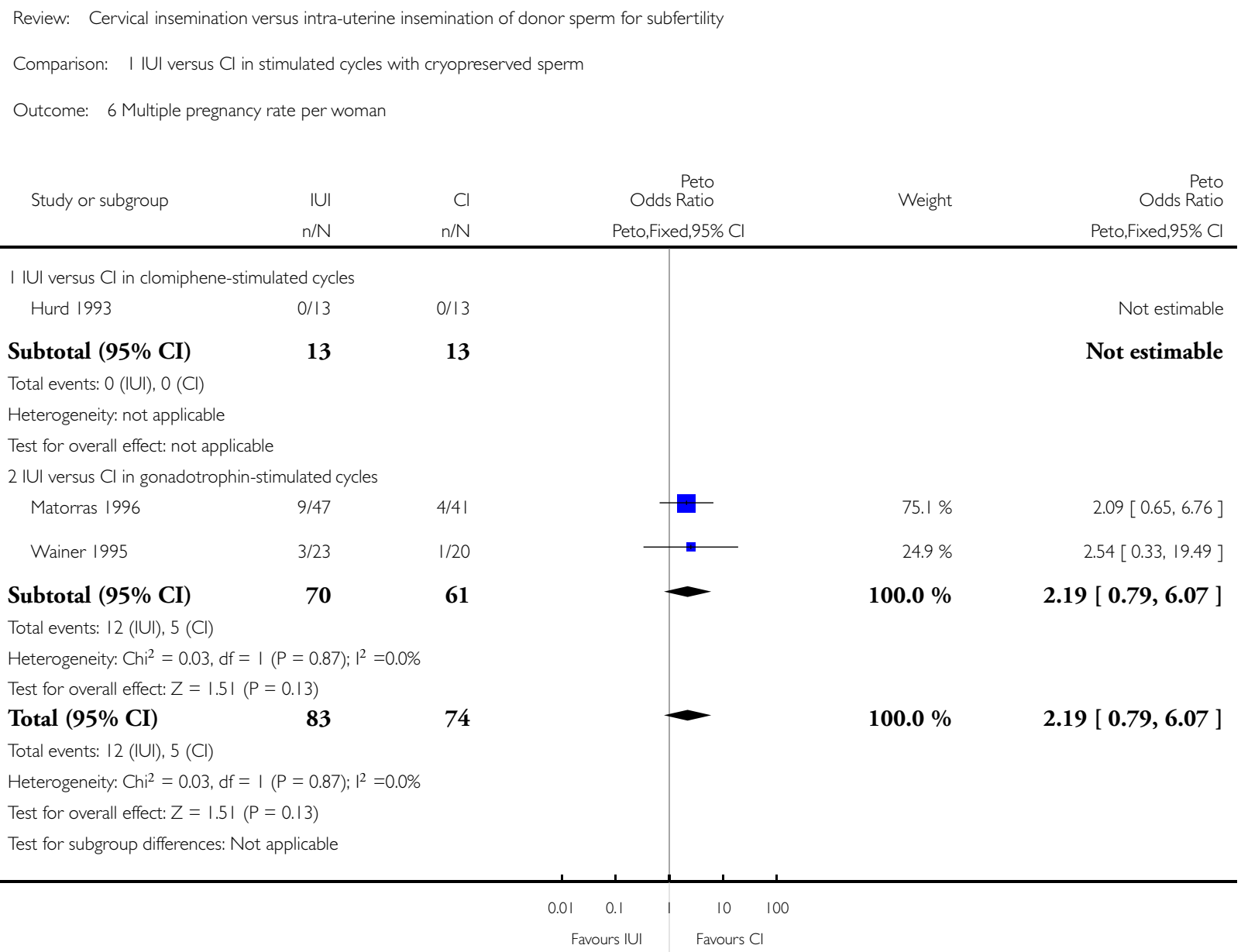

\section{ADDITIONAL TABLES}

Table 1. Study quality

\begin{tabular}{|c|c|c|c|c|c|}
\hline Study & $\begin{array}{l}\text { Secure randomisa- } \\
\text { tion }\end{array}$ & $\begin{array}{l}\text { Adequate conceal- } \\
\text { ment }\end{array}$ & Intention to treat & Losses to follow up & Notes \\
\hline Hurd 1993 & $\begin{array}{l}\text { Yes, random num- } \\
\text { bers list }\end{array}$ & $\begin{array}{l}\text { Using opaque con- } \\
\text { secutively numbered } \\
\text { envelopes }\end{array}$ & Yes & None & $\begin{array}{l}\text { Local funding, i.e. un- } \\
\text { funded }\end{array}$ \\
\hline
\end{tabular}


Table 1. Study quality (Continued)

\begin{tabular}{|c|c|c|c|c|c|}
\hline Mattoras 1996 & $\begin{array}{l}\text { Yes, random number } \\
\text { table }\end{array}$ & $\begin{array}{l}\text { Using opaque con- } \\
\text { secutively numbered } \\
\text { envelopes }\end{array}$ & No & None & Public funding \\
\hline Patton 1992 & $\begin{array}{l}\text { Random assignment, } \\
\text { method unclear }\end{array}$ & Unclear & No & $\begin{array}{l}\text { Dropouts: } 9 \text { ICI and } \\
10 \text { IUI }\end{array}$ & - \\
\hline Wainer 1995 & Yes, randomised lists & Unclear & Unclear & Not stated & - \\
\hline
\end{tabular}

\section{WHAT'S NEW}

Last assessed as up-to-date: 16 February 2008.

\begin{tabular}{l|l|l}
\hline Date & Event & Description \\
\hline 20 September 2010 & Amended & Contact details updated. \\
\hline
\end{tabular}

\section{H I S T O R Y}

Protocol first published: Issue 4, 1998

Review first published: Issue 4, 1998

\begin{tabular}{lll}
\hline Date & Event & Description \\
\hline 6 November 2008 & Amended & Converted to new review format. \\
\hline 17 May 2007 & New search has been performed & This review was updated May 2007 \\
\hline 17 February 2008 & New citation required and conclusions have changed & Substantive amendment \\
\hline
\end{tabular}




\section{CONTRIBUTIONSOFAUTHORS}

Besselink DE: took the lead in updating the review; completed literature search, selected trials and performed data extraction and analysis; wrote the review.

Marjoribanks J: as the second review author assisted with updating the review, selected trials and performed data extraction.

Farquhar C: assisted in updating the review and acted as referee when first and second review authors disagreed on inclusion of trials.

Kremer JAM: acted as a clinical expert.

Paul O'Brien: was the original author of the review.

\section{DECLARATIONSOF INTEREST}

None

\section{SOURCES OF SUPPORT}

\section{Internal sources}

- No sources of support supplied

\section{External sources}

- Radboud University Nijmegen, Faculty of Medical Sciences, Netherlands.

- Stichting Nijmeegs Universiteitsfonds, Netherlands.

\section{NOT E S}

This review has been withdrawn as it was published over two years ago and an updated review has not yet been submitted.

\section{NDEX TERMS}

\section{Medical Subject Headings (MeSH)}

Cervix Uteri; Cryopreservation; Insemination, Artificial, Heterologous [ ${ }^{*}$ methods]; Pregnancy Rate; Randomized Controlled Trials as Topic; Semen Preservation [methods]; Uterus

\section{MeSH check words}

Female; Humans; Pregnancy 